2019

\title{
Using FOI to explore governance and decision-making in the UK
}

Sheaff, Mike

http://hdl.handle.net/10026.1/14428

Routledge

All content in PEARL is protected by copyright law. Author manuscripts are made available in accordance with publisher policies. Please cite only the published version using the details provided on the item record or document. In the absence of an open licence (e.g. Creative Commons), permissions for further reuse of content should be sought from the publisher or author. 


\section{CHAPTER 4}

\section{Using FOI to Explore Governance and Decision-Making in the UK}

Mike Sheaff

\section{Introduction}

This chapter considers use of freedom of information (FOI) legislation in researching decision-making by those in authority within a context of declining public trust in elites and simultaneous demands for greater transparency. A particular focus is the use of FOI as a tool for social research, and its relationship with investigative journalism. The chapter begins with a summary of the use of FOI in UK social research, before introducing examples of FOIA requests by others, including journalists. This is followed with an account of my own use of FOI to explore decision-making in a failed public service contract in the UK. A concluding discussion considers the potential for using FOIA as a tool for research beyond the collection of information, to support a more critical exploration of decision-making within state organisations, with some final comments on the relationship between social research and investigative journalism.

The British state has a long history of secrecy. In 1971, the Labour Minister Richard Crossman described secrecy as the, 'real English disease and in particular the chronic ailment of the British Government' (Crossman 1971). This tradition was challenged in 1998 with the publication of a Government White Paper, Your Right to Know, which proclaimed: 'Openness is fundamental to the political health of a modern state. This White Paper marks a watershed in the relationship between the government and people of the United Kingdom. At last there is a government ready to trust the people with a legal right to information' (Chancellor of the Duchy of Lancaster 1998). This resulted in the UK Freedom of Information Act 2000, which came into effect in 2005. An estimated 121,000 requests were made in the first year of operation of the Act (Colquhoun 2010); non-central government bodies received about 87,000 of these, of which approximately 60,000 were submitted to local authorities (Colquhoun 2010). The process of seeking disclosure through FOIA requests in the UK involves up to five stages:

1. Request for disclosure to a public authority

2. Request for Internal Review by the public authority

3. Complaint to Information Commissioner (resulting in a Decision Notice)

4. Appeal to Information Rights Tribunal (Lower Tier)

5. Appeal to Information Rights Tribunal (Upper Tier) (on points of law only)

Despite the promise of openness, of 46,681 FOI requests received by central governmental bodies in 2017, 17,309 were withheld in full or in part. In $29 \%$ of cases this was due to the cost exceeding the allowable limit, and $2 \%$ were judged vexatious or repetitious. The remaining 12,643 (68\%) were withheld on the grounds that one or more of twenty-three statutory exemptions applied (Cabinet Office 2017). Some exemptions are absolute, but most are qualified, meaning that a decision not to disclose is subject to a public interest test. Forty seven percent of the 12,643 FOIA requests received by central government in 2017 that were refused on the grounds that the information sought was deemed to be 'personal data' and consequently exempt under s40 (Cabinet Office 2017). I return to this issue, a when exploring organisational decision-making, the boundary between personal and collective responsibility can be complex. Before considering the 
determination of 'public interest', the following section reviews examples of UK research in which FOIA has been used.

\section{Accessing information: FOIA and social research in the UK}

There are now several examples of such research, but referring to an observation by Brown (2009), Savage and Hyde (2013) note suggestions "that researchers are yet to fully appreciate the value of FOIA to empirical research in the fields of social science and law" (2013: 303). A common feature of existing research is the collection of comparative data across public authorities, including Savage and Hyde's (2013) own study of whistleblowing. This involved requests to 48 food safety regulatory bodies to identify whether the regulators were receiving whistle-blowing disclosures, and what action resulted from such disclosures. Savage and Hyde note, "FOIA request are particularly useful where comparisons are sought to be drawn between various public authorities. By using a standardised FOIA request, data obtained from public authorities can be standardised" (Savage \& Hyde 2013: 309).

Similarly, Johnson and Hampson (2015) sent FOIA requests to police forces in England as part of a larger research study of criminal activity and EU migrants. Over a fifteen-month period, 43 forces were asked to disclose information relating to criminal charges, the type of crime, and the nationality and age of the alleged offenders. While noting limitations, the authors' overall conclusion was that, "access afforded by the FOIA is valuable. Research conducted would not have been possible without this formal mechanism to obtain the required data; results received have been useful, interesting and informative" (Johnson \& Hampson 2015: 263).

In the context of social work research, Murray (2013) investigated free access to leisure centres for children in care through requests to all 152 local authority children's services in England. Results showed a differential provision, "with fewer than half of councils (48 per cent) currently providing free leisure passes" (Murray 2013: 1347). Murray also comments on limitations in use of FOIA, including difficulties in asking extensive questions and probing responses, and potentially a reluctance by some authorities to comply (although this was not experienced in this study). Murray concludes, "these limitations notwithstanding, there are many advantages associated with using Freedom of Information requests. It is suggested that it be considered a suitable way to elicit data across a range of social work topics" (Murray 2013: 362). A review of use of FOIA requests in research involving the English NHS described the number of studies as "relatively few" (Fowler et al. 2013: 6). Sixteen studies conducted between 2005 and 2013 had requested disclosure on a diverse range of issues, including litigation, surgical provision, funding for rarer cancers, laboratory provision, pharmaceutical safety, and midwifery discipline. These studies involved a total of 1732 requests, with a median of 86 per paper, and the review noted, "questions were being asked across a cross-section of the NHS" (Fowler et al. 2013: 4).

Use of FOIA in UK research has prompted discussion on ethical implications, particularly relating to informed consent, confidentiality and anonymity. Use of FOIA may increase response rates - one study achieved an $83 \%$ response rate using FOIA compared to $11 \%$ when informal request letters were sent (cited in Fowler et al. 2013) raising the question of whether use of a statutory tool in this way is ethically justified. In the context of clinical research, objections have been that "researchers [are] using the Act 
to compel hospitals to provide data to further their research" (Breathnach, Riley \& Planche 2011). The fundamental concern is whether use of a statutory entitlement to obtain data strikes against the ethical principle of informed consent to participate in research, since "national and international guidance states that participation in research must be voluntary". The authors argue consideration should be given to "the ethical and resource implications of compelling colleagues to participate in research, even if such compulsion is permitted in law" (Breathnach, Riley \& Planche 2011: 1).

This objection deserves attention, but context is important. The concerns arose in the context of FOIA requests from a tobacco company for research data on smoking and young people from a British University, and the authors' own experiences of attempts to disclose hospital research data. Conducting research without consent can be considered in some ways analogous to covert research, about which the British Sociological Association's Statement of Ethical Practice observes:

There are serious ethical and legal issues in the use of covert research but the use of covert methods may be justified in certain circumstances.... Researchers may also face problems when access to spheres of social life is closed to social scientists by powerful or secretive interests (British Sociological Association 2017, para 14).

On confidentiality and anonymity, Savage and Hyde (2013) suggest that freedom of information requests 'fall outside the traditional dichotomy between primary and secondary research', as it involves publicly available data but this status is achieved solely as a consequence of the researcher's requests. They suggest this has prompted concern from some ethics committees, defining the data as primary data generated by the researcher. However, Savage and Hyde argue there is an important difference:

In the FOIA scheme the responsibility for cleansing the data of personal information lies with the public authority to which the request is made. The data provided in response to a FOIA request should not contain information that identifies any person, living or dead. If this is not possible then the request should be refused by the public authority. Therefore, research conducted through FOIA requests will not pose ethical issues in the same way as research where data is gathered directly by the researcher (Savage \& Hyde 2013: 310).

The examples described above used FOIA requests as a form of survey technique, directed towards collecting cross-organisational comparative data. But in this chapter I consider its use in ways more analogous to qualitative research, involving follow-up questions and probing that raise ethical issues beyond those discussed by Savage and Hyde (2013). This is a method more frequently adopted in non-research contexts, by journalists, politicians and citizens. Here, requests have been prompted by suspicions that information is being concealed to protect the organisation and individuals from potentially embarrassing revelations, or to avoid public scrutiny of decisions. Three examples are described in the next section, considered in the context of 'personal privacy' and 'private spaces'.

Freedom of information versus personal privacy: the 2009 MP's expenses scandal 
One social history of American newspapers suggests an early congruence, explaining that, 'reporters in the 1890's saw themselves, in part, as scientists uncovering the economic and political facts of industrial life more boldly, more clearly, and more "realistically" than anyone had done before' (Schudson, 1978: 71). But perceptions of excessive intrusion, described as muckraking by President Theodore Roosevelt, were accompanied by claims for protection of the 'right to privacy': 'The press is overstepping in every direction the obvious bounds of propriety and of decency.' (Warren and Brandeis, 1890: 196). "Objective" journalism' became the norm, until the rebirth of investigative reporting in the late 1950's and early 1960's'. (Weaver and McCombs, 1980: 488).

An early conflict in the UK between transparency and privacy developed following FOIA requests by journalists and others for details of allowances claimed by members of parliament. The request was rejected on the grounds that the information was the 'personal data' of the subject, a position maintained following internal review. The journalist appealed to the Information Commissioner, and there followed a highly protracted communication between the IC and HoC lasting eighteen months. In a Decision Notice issued in June 2007, the Information Commissioner summarised the view of the House of Commons authority:

It considered the information to be exempt under section 40(2) of the Act because it was personal data about the MP concerned. The House maintained that disclosure would breach the requirement of the first Data Protection Principle that personal data be processed fairly and lawfully (Information Commissioner DN FS50070469, para 6) ...disclosure of this information in the detail sought would compromise the privacy of the MP and his or her family and that there can be personal security risks in disclosing where a MP lives (para 10).

In contrast, the Information Commissioner took the view:

the link with holding public office is clear. If individual MPs had not been elected to carry out their role as public representatives they would not be entitled to claim the related expenses.... It is only because such costs are considered to be expenses arising from the holding of public office that they are subject to reimbursement from the public purse (para 32).

The House of Commons authority appealed to the Tribunal on several requests, which upheld the Information Commissioner's decision, concluding there is, "a balance between competing interests broadly comparable, but not identical, to the balance that applies under the public interest test for qualified exemptions under FOIA." (The Corporate Officer of the House of Commons v Information Commissioner and Norman Baker MP, EA/2006/0015 \& 0016, para 90). An appeal by the House of Commons to the High Court was unsuccessful. Confirming that there are circumstances where public office is involved when it may be fair to reveal personal information under FOIA, the court upheld the earlier instruction to disclose the material with appropriate redactions. In Spring of 
2009 , leaks from some of the documents began to appear in the media, including revelations about $£ 116,000$ claimed by the Home Secretary for a 'second home' that was her family residence. It seemed that while disclosure of MPs' expenses, 'followed a fouryear campaign by journalists using FOI laws ... (these) worked alongside a very oldfashioned form of information provision, a leak.' (Worthy, 2014: 27). As BBC journalist Martin Rosenbaum commented, subsequent more extensive revelations by the Daily Telegraph, 'would not have happened without the FOI Act, that is clear. Yet they are actually based on a leak, not legally-enforced disclosure. So some of today's revelations may be as much as about leaking, or "chequebook journalism", as about freedom of information' (Rosenbaum, 2009). Another interpretation of these later reports, unlike the early leaks, describes them as a departure from conventional journalism. 'Those initial leaks, based on a sample of the redacted data, conformed to the traditional journalistic model of identifying scandalous individuals, rather than reporting expenses more systematically. Yet those working on the redacted data thought that the abuses they were processing were systemic and not to be easily identified as 'fingering' corrupt individuals' (Ruppert and Savage, 2011: 75). Those involved in leaking the un-redacted material consequently demanded wholesale publication, a condition refused by several newspapers, until, 'the Daily Telegraph, with its unusually large corps of political journalists thought it could devote the resources to allow a comprehensive treatment.' (Ruppoer and Savage, 2011: 76). Importantly, this included details of private addresses, which would have been redacted under the High Court judgment. As this would have removed information that enabled revelations about MP's claims for different accommodation addresses, the BBC's Martin Rosenbaum noted at the time: 'the Telegraph today argues that without these addresses, the newspaper would not have been able to shed light on some of the questionable practices it reveals.' (Rosenbaum, 2009). Publication of the un-redacted details sold to the Daily Telegraph had significant repercussions, with resignations by Ministers and the House of Commons Speaker, and criminal investigations into eight parliamentarians, four of whom were jailed. The scandal reached the scale that it did, to a considerable extent because 'personal information' that would have been redacted, notably MP's addresses, was leaked. How far individuals in positions of authority can reasonably expect typical expectations of privacy to apply to them is a question to which I return. Before this, the next section considers two examples where the British government refused disclosure of information on the grounds that official deliberations on sensitive issues needed to be conducted in a 'private space'.

'Private spaces' for official deliberations: use of the government veto In common with most FOI systems, the UK allows a government veto on disclosure, creating a rare opportunity for the executive to over-rule a judicial decision. The first use of this provision came in the wake of the invasion of Iraq, with a request from a citizrn, Dr Christopher Lamb, for disclosure of Cabinet minutes and meeting records from March 2003. These concerned the provision of legal advice by the Attorney-General on military action against Iraq. The Cabinet Office refused disclosure on public interest grounds, arguing the need for confidentiality surrounding policy development and ministerial communications. The Information Commissioner subsequently identified significant public interest factors favouring disclosure: 
These included the gravity and controversial nature of the decision to go to war against another country and the particular public interest in transparency given the controversy surrounding the Attorney General's legal advice on the legality of the military action in question. The Commissioner did not consider that the information in the public domain sufficiently enabled the public to scrutinise the manner in which the decision was taken and took the view that disclosure of the Minutes was necessary to understand that decision more fully (Information Commissioner 2009: 8).

The Cabinet Office appealed to the Tribunal, which by 2-1 majority decided that on balance the public interest favoured disclosure of the minutes. The Tribunal described this as:

an exceptional case, the circumstances of which brought together a combination of factors that were so important that, in combination, they created very powerful public interest reasons why disclosure was in the public interest. It was this that led the majority of the panel to conclude that they were at least equal to those in favour of maintaining the exemption (Information Commissioner 2009: 11).

On 23 February 2009 Jack Straw, Secretary of State for Justice, issued a "veto" certificate under section 53(2) of the Act to overrule this decision. Essentially, his argument was that Cabinet discussions need the protection of a 'private space' to allow free and frank debate:

Dialogue must be fearless. Ministers must have the confidence to challenge each other in private ... To permit the commissioner's and the tribunal's view of the public interest to prevail would, in my judgement, risk serious damage to Cabinet government - an essential principle of British parliamentary democracy (Ministry of Justice 2009).

A similar argument was employed in applying the veto to documents relating to the Coalition Government's re-organisation of the NHS in 2011-12. Here the request was submitted by a politician, John Healey MP, a former Labour health spokesperson. A significant focus was upon requests for disclosure of a Transitional Risk Register (TRR), created as part of the Department of Health's (DH) risk assessment of the proposed changes. DH refused on the grounds that "disclosure would or would be likely to inhibit the free and frank provision of advice". As a qualified exemption, Mr Healey requested an internal review. DH maintained its refusal but changed the justification, now suggesting the requested information was exempt from disclosure as it was concerned with the formulation and development of government policy. This is also a qualified exemption, and DH maintained its position that the public interest favoured nondisclosure.

Mr Healey complained to the Information Commissioner, who in accepting the risk register was potentially exempt went on to consider the public interest test. Against $\mathrm{Mr}$ Healey's claim that there was an important public interest at issue, as disclosure would allow greater scrutiny of the government's plans, DH claimed disclosure would jeopardise success of the policy through inhibiting frank discussion. Concluding the 
arguments were finely balanced, the IC judged the information should be disclosed, explaining:

there is a very strong public interest in disclosure of the information, given the significant change to the structure of the health service the government's policies on the modernisation will bring. There has also been widespread debate public debate amongst the general public, commentators, experts and those who work in the NHS.... Disclosure would significantly aid public understanding of the risks related to the proposed reforms and it would also inform participation in the debate about the reforms (ICO DN FS50390786, para 31).

DH appealed the decisions to the Information Tribunal, which accepted "a safe space is required for government to formulate and develop policy", but argued the significance of this would change over time (para 59). A former Cabinet Secretary and the DH Permanent Secretary advised the Tribunal that disclosure would inhibit thinking and consequently damage sound policy making. The Tribunal rejected this reasoning, commenting, "there was no actual evidence of such an effect" (para 66), noting research by the Constitution Unit at University College London that found little evidence that FOIA has what is described as a "chilling effect" on discussion.

DH's position was described by the Tribunal as, "tantamount to saying that there should be an absolute exemption for risk registers at the stages the registers were requested in this case" (para 73). By establishing the relevant exemption as qualified, Parliament had made it subject to a public interest test, and the Tribunal concluded that the public interest justified disclosure:

the NHS reforms were introduced in an exceptional way. There was no indication prior to the White Paper that such wide ranging reforms were being considered. The White Paper was published without prior consultation. It was published within a very short period after the Coalition Government came into power. It was unexpected. Consultation took place afterwards over what appears to us a very short period considering the extent of the proposed reforms.... Even more significantly the Government decided to press ahead with some of the policies even before laying a Bill before Parliament' (para 85)... 'We find the weight we give to the need for transparency and accountability in the circumstances of this case to be very weighty indeed (para 89).

The Tribunal decision was published on 5th April 2012, and on 8 May was over-ruled by the Secretary of State for Health, vetoing disclosure. He explained that, "there is already a considerable amount of material in the public domain on risks involved in the reform programme", suggesting, "there was a significant risk" that "disclosure of the TRR at this time would in fact have distorted debate and understanding" (Information Commissioner 2012: 28). The Information Commissioner's subsequent report to Parliament noted: The previous three occasions on which the veto has been exercised related to the disclosure of Cabinet material under FOIA. The Commissioner would wish to record his concern that the exercise of the veto in this case extends its use into other areas of the policy process. It represents a departure from the position adopted in the Statement of 
Policy and therefore marks a significant step in the Government's approach to freedom of information (Information Commissioner 2012: 19-20).

Both these examples concerned attempts to disclose how decisions were made by government, and the evidence used to inform the outcomes. Social and institutional practices, rather than the alleged wrongdoing of individuals, provides the focus. While the example of the MP's expenses is significant for establishing a balance between protection of personal information, transparency and public accountability, requests for the Iraq war legal advice and the NHS risk register perhaps offer examples of more direct relevance for social researchers.

\section{Using FOIA to Research a Contracting Failure}

For three decades British governments have pursued policies favouring the contracting of public services to external organisations. 'Government outsourcing and contracting has become a very significant part of the delivery of central and local government services throughout the world. The UK Government spends $£ 251.5$ billion per year on outsourcing and contracting' (House of Commons Public Administration Committee Constitutional Affairs, 2018). Despite this representing approximately one-third of public spending, it can be difficult to subject these contracts to effective scrutiny.

This became apparent with the collapse of several high-profile contractors, seemingly unanticipated by the relevant public authorities. A lack of awareness of Southern Cross's financial difficulties until its collapse in 2011 was repeated on an even larger scale with Carillion in 2018. Holding around 420 public sector contracts, 'by value, Carillion was central government's sixth largest supplier in 2017.' (National Audit Office, 2018: 6). This included facilities management, catering, road and rail maintenance, accommodation, consultancy, and construction. Since 2013 the Cabinet Office regularly raised with Carillion its delayed payments to sub-contractors, but, 'the scale of the losses announced on 10 July 2017 came as a surprise to the Cabinet Office as it contradicted previous discussions with Carillion and market expectations' (NAO, 2018: 7). Although the Cabinet Office subsequently 'took steps to improve its information about Carillion's financial health', the company went into compulsory liquidation in January 2018. Interserve, a company employing ' 45,000 staff in the UK working on $£ 2$ bn worth of government contracts' went into administration in March 2019. The GMB trade union claimed Interserve received public contracts valued at $£ 660 \mathrm{~m}$ 'in the run-up to going into administration, in an apparent repeat of the Carillion fiasco' (Brignall, 2019). One of the obstacles to gaining better knowledge and understanding of these episodes is the exclusion of public service contractors from the freedom of information legislation. This is the subject of considerable debate in Britain, with the Information Commissioner recently urging that, 'Freedom of information legislation should be extended to enable greater transparency in the delivery of public services. This would promote democratic accountability but also act as a driver for improving contractual oversight and service delivery.' (Information Commissioner, 2019). FOIA does nevertheless apply to the contracting public authorities themselves. Drawing upon my own research using FOIA to study a contracting failure, this section describes elements of the experience, including opportunities it presents and obstacles that can be encountered (Sheaff, 2016; Sheaff, 
2017). Attention to the latter relates my experiences to potential pitfalls encountered in FOIA research described by Lippert, Walby and Wilkinson (2016). First, I provide a contextual background to my own study, the origins of which did not lie in a conventional research proposal, but through a role I held as a Non-Executive Director in a NHS Primary Care Trust (PCT) in South West England.

Setting the scene: 'hierarchies of credibility'

In 2010, the newly-elected Coalition Government's plans for NHS reorganisation involved abolition of existing organisations - including PCT's and Strategic Health Authorities (SHA's). As previously noted, the plans generated widespread controversy, in part because the implementation of change (including 'clustering' of PCT's and SHA's) began prior to the proposals gaining parliamentary approval (on which, see also House of Lords, 2013). The pace of change was rapid, with little opportunity for meaningful challenge. In a letter to the Chair of our PCT 'Cluster' in June 2011 I explained my concerns, concluding, 'Unlike previous NHS reorganisation, 'clustering' has not been subject to Parliamentary scrutiny, which arguably means we have greater responsibilities in our role of Non-Executive Directors to contribute to achieving public confidence in future arrangements'.

The tempo of change continued, with the government's reforms intended to promote competition across health and social care. The 'Cluster' Chair had substantial NHS experience, having been a chief executive of a Strategic Health Authority, and subsequently Chair of a social enterprise delivering a NHS contract, Secure Healthcare Ltd (SHL). I enquired about the governance arrangements for this organisation. My interest was stimulated having learned of it being awarded a $£ 130,000$ start-up grant by the Department of Health, winning a $£ 5$ million contract with Wandsworth PCT to provide health services at Wandsworth Prison, but collapsing little more than two years in September 209 with debts of over $£ 1.5$ million. My questions to its former Chair were forwarded to the South West SHA, and my PCT Chair was asked by the SHA Chair to discourage me from pursuing my concern. I was described as causing 'disruption' to the NHS reorganisation.

In response, in September 2011 I wrote to the SHA, copying local MP's, explaining why I believed this episode, 'reveals important insights into how decisions have been made at different levels within the NHS . . from which there are important lessons that we should be prepared to learn.' The SHA forwarded my letter to the Appointments Commission (AC), the body responsible for appointing NHS Non-Executive Directors, which established a review into my concerns. The subsequent report gave particular attention to the SHL contract, with an overall assessment that 'the underlying reason for the failure of SHL were typical reasons for business failure' (Appointments Commission, 2011: 11). In so far as reasons were explored, responsibility was directed at subordinate organisational levels. SHL's bid team were judged to have 'let down the company', and Wandsworth PCT was criticised for demonstrating, 'poor procedures and many failings in management'. Very different assessments were made of those in more senior roles. The investigation concluded that problems experienced by SHL 'were addressed by the management of the company as they arose; without success as it turns out.' Strong endorsement is given to processes for approving DH funding, described as 'thorough, 
independent, open and externally reviewed', and subject to, 'due diligence from the outset'.

This report was described by the AC chief executive as 'supported by robust evidence' and 'well argued', and by the SHA Chair as 'very detailed', 'thorough' and 'rigorous'. The SHA Chair informed local MP's that having taken 'two months to complete and involved the review of over 450 pages of documents from 45 personal and organisational reference sources' the review had concluded my concerns were 'completely unfounded'. In response, I used the NHS complaints procedure to argue my concerns were not adequately addressed. This too was dismissed, and an appeal to the Parliamentary \& Health Service Ombudsman met the response that as a "personnel" matter it was outside their jurisdiction. My member of parliament requested a meeting with me and the Health Minister to discuss the contract, but was told: "You ask that I meet with you and $\mathrm{Mr}$ Sheaff to discuss his continuing concerns. I regret I have to decline . . . there is nothing I can usefully add to the various independent investigations that have been conducted on this matter. . I regret that Mr Sheaff continues to have concerns over this matter, but am of the view that we have devoted as much attention to his concerns as can reasonably be expected under the circumstances." (Correspondence to Oliver Colvile MP, February 2014).

This response from a government minister illustrates what Becker described as a 'hierarchy of credibility,' wherein, 'participants take it as given that members of the highest group have the right to define the way things really are'. (Becker, 1967: 241).

Perceptions 'that those at the top have access to a more complete picture of what is going on than anyone else', align with views, that, 'Members of lower groups will have incomplete information, and their view of reality will be partial and distorted in consequence.' A consequence is that, 'any tale told by those at the top intrinsically deserves to be regarded as the most credible account obtainable of the organizations' workings'. (Becker, 1967: 241). My move in role from participant to researcher was prompted by Becker's recognition that, 'credibility and the right to be heard are differentially distributed through the ranks of the system. As sociologists, we provoke the charge of bias, in ourselves and others, by refusing to give credence and deference to an established status order, in which knowledge of truth and the right to be heard are not equally distributed.' (Becker, 1967: 242).

'Truth' is inevitably contested, and my goal was twofold. First, to use FOIA requests relating to the collapse of SHL to go beyond official accounts, taking the opportunity to engage in what Laura Nader described as 'studying-up' to uncover behaviour in 'powerful institutions and bureaucratic organisations' (Nader, 1969/1972: 292). For this, I drew upon Diane Vaughan's concepts of organisational deviance and routine nonconformity, involving deviation 'from both design goals and normative standard or expectations' (Vaughan, 1999: 273). Alongside this, I wanted to explore opportunities for using FOIA disclosures as a route for uncovering an example of what Vaughan terms 'clean-up work', through which organisations seek to 'prevent incidents of routine nonconformity from being publicly defined as mistake.' (Vaughan, 1999: 287).

Official accounts and information disclosures

Over a period of more than eighteen months, I made twenty three requests to nine public authorities, including the SHA, DH, two NHS Trusts, the Appointments Commission, 
and the Cabinet Office. Nine of the requests were followed by requests for internal reviews, of which two continued to appeals to the Information Commissioner and the Information Rights Tribunal. This process contributed to my experiences of 'stalls' (Lippert, Walby and Wilkinson, 2016), where information was disclosed through a very slow and frequently protracted process. Nevertheless, by providing new insights, several disclosures prompted further requests to other organisations. Through gradually piecing these together an alternative perspective emerged to that offered in official accounts. Illustrative examples are provided here to present an alternative representation of the demise of SHL, directing attention upwards in the organisational hierarchy rather than to those at more junior levels. The first concerns the official assessment that that problems 'were addressed by the management of the company as they arose', whereas SHL's bid team 'let down the company'. SHL's accounts are cited as evidence of the organisation's financial stability: 'A review of the accounts of Secure Healthcare Ltd for the first year of its operation show a solvent organisation with sufficient resources to meet its liabilities . . . There was no immediately obvious sign of the difficulties that later arose in making payments to creditors at this point.' (Appointments Commission, 2011: 11). A different picture is revealed from FOIA disclosures by two NHS Trusts to which SHL subcontracted services. By March 2008, nine months into the contract, SHL's debts to these Trusts amounted to $£ 532,822.75$. Twelve months later, this had risen to $£ 556,222.00$ (over one-tenth of the contract's total value), and to $£ 648,565$ by the time SHL collapsed in September 2009. It appears none of this was known to Wandsworth PCT, which from April 2008 had been making advance payments to SHL, in contravention of financial procedures. After further advance payments, on 21 July 2008 SHL informed the PCT, 'we do not have sufficient funds to cover our July payroll'.

However, in the same month, SHL was awarded a government loan of $£ 400,000$, 'to bid for and deliver upcoming prison healthcare contracts'. $£ 259,000$ was drawn down, and subsequently written off. The Cabinet Office responded to a FOIA request with a statement that the decision on the loan 'included a review of previous accounts, financial systems, and cashflow forecasts.' But SHL's first and only set of accounts were not approved until 5th February 2009. On the previous day, the Department of Health awarded SHL a grant of $£ 380,000$ for a new training campus. Yet, seven months later, on 9th September, the SHL Board received a report from its chief executive, disclosed by $\mathrm{DH}$ in response to a FOIA request. This advised the Board of: 'serious liquidity issues ... A number of factors have contributed to the current crisis position. It is clear we have had poor financial information to track our progress and limited cost controls ... our cost control and management data has been poor from day one ... The grant and loan income injections masked the overspending ... The Wandsworth cost over-runs were not addressed.' Writing about the training campus, SHL's Board was informed: 'We went ahead with [this] development without a tested business plan'.

Some of the most significant data obtained through FOIA disclosures concerned the role of the Department of Health, revealing a considerably closer relationship with SHL than is suggested in official accounts. One document records two payments totalling $£ 220,770$ made as part of a 'service level agreement' between DH and SHL. These included costs of seconding a DH employee to SHL as a 'project manager'. As these figures did not correspond with SHL's accounts I requested an internal review, receiving details of three 
more payments. These amounted to $£ 2,205,882.50$, with the final payment - of $£ 1,457,882.50$ - made twelve days before SHL went into liquidation. According to subsequent correspondence with a government Health Minister, the first reference in DH's own records to SHL's debts was on 14th September 2009, just two days before its collapse. Despite this, the official investigation into my original questions about DH funding concluded: 'The means by which applications were assessed and due diligence conducted from the outset ... was thorough, independent, open and externally reviewed. An investment committee was put in place that had responsibility for approving investments independently of the Department.' (Appointments Commission, 2011: 6). In her analysis of organisational failure, Vaughn uses the term 'structural secrecy' to describe: 'the way that patterns of information, organizational structure, processes and transactions, and the structure of regulatory relations systematically undermine the attempt to know and interpret situations in all organisations." (Vaughan, 1996: 238). In the case of SHL, disclosed data revealed that neither the PCT nor DH had knowledge of SHL's debts until it was on the very brink of collapse. Together with failures in information flow, correct procedures were not always followed. 'Normalization of deviance' is a concept used by Vaughan to describe a gradual process of adopting unacceptable practices which, in the absence of negative consequences, become the norm. Examples in this episode are advance payments made by the PCT to SHL, and the apparent lack of rigour shown by government in awarding grants, a loan, and establishing a 'service level agreement'. The context for this was the government's enthusiasm for establishing a market within health care, and an audit review commissioned by one of the two sub-contracting NHS Trusts refers to, 'considerable enthusiasm from DH downwards for a social enterprise model of care'. Documents such as these provide valuable insights into decision-making, and the role of culture alongside organisational structures in inhibiting more rigorous scrutiny.

There is no cause to believe errors and omissions in the official investigation were deliberate in any way. Its assessment was based upon documents that were in the public domain. Only through use of documents released in response to FOIA requests could an alternative account be constructed. Without this, the hierarchy of credibility afforded protection to a deeply flawed analysis. This prompted a second strand in my research, in an attempt to explore processes of concealment achieved through 'clean-up work'.

Lifting the veil on 'clean-up work'

Becker urged social researchers to 'doubt everything anyone in power tells you' (Becker, 1998: 91). This is not founded upon personal mistrust, but his view that, 'institutions always put their best foot forward in public ... . social organization gives them reasons to lie' (Becker, 1998: 91). One consequence, as he had written earlier, is that, 'by refusing to accept the hierarchy of credibility, we express disrespect for the entire established order. We compound our sin and further provoke charges of bias by not giving immediate attention and "equal time" to the apologies and explanations of official authority' (Becker, 1967: 241-242). In a sense, I sought to turn this on its head, giving attention to processes used by those in authority to marginalise discrepant voices. And it was within this focus of the research that I met some of the greatest obstacles to disclosure, including examples of 'shutdown' (Lippert, Walby \& Wilkinson, 2016). 
At an early stage the SHA declined to communicate with me other than through a lawyer, who maintained my concerns were without basis. In October 2012 he explained, 'My Client is satisfied that the concerns you raised have been fully investigated and that they are unfounded.' In December he reiterated, 'You make reference . . . to the concerns you raised regarding Secure Healthcare. As I stated in my email of 2 October, my Client is satisfied that such concerns have been fully investigated and that they are unfounded.' Seeking a better understanding of how my concerns had been handled, I submitted FOIA requests for three documents created at the time I informed the SHA of my concerns, in September 2011. These included the transcript of a telephone conference call involving the SHA Chair and my PCT Chair, and a letter from the SHA Chair to the Appointments Commission.

The SHA informed me that all relevant documents were with the lawyer, to whom I should submit my request. I did so, but no information was disclosed. The lawyer told me the letter could not be found, and when I asked what search had been conducted, he wrote, 'You have been informed that the letter you were seeking cannot be found. That is the end of the matter.' (12 April 2013). This experience came closest to what Lippert, Walby and Wilkinson (2016) describe as 'shutdown', involving a permanent locking of information, but I requested an internal review, which was handled by the SHA's Information Officer who was more helpful. The telephone transcript, with some redactions, was disclosed to me, a matter of days before the SHA was abolished, following a decision by the Information Officer to treat my request as a subject access request under the Data Protection Act. He considered that the conversation about me was my own personal data, to which I was entitled. On the letter I was told, 'I have reviewed our files and we cannot find a copy of (the) letter ... I think the quickest and easiest way to find if the letter is held in archive would be a FOI request directly to the Department of Health'.

This was to present one of the most challenging responses to my FOIA requests, resulting in appeals to the Information Commissioner and the Information Rights Tribunal. The outcome of my request to the DoH was summarised in the Tribunal's judgment: 'DoH provided a heavily edited copy, which contained almost nothing of substance. It relied on s.40(1), as regards the personal data of MS and s.40(2) as to the personal data of three third parties. It modified its position to a limited extent when complying with MS's request for an internal review by removing redactions relating to matters that were clearly not personal data.' (Sheaff and The Information Commissioner \& the Department of Health, EA/2014/0005). Included in the respondent's bundle for the hearing was a statement from the former SHA Chair urging non-disclose of the redacted sections: "we clearly expect the Secretary of State to firmly protect us and our reputations in the proper execution of our duties as leaders within the NHS.' While noting the 'the entirely legitimate purposes of MS's quest for greater transparency and accountability', the Tribunal upheld the Information Commissioner's decision:

'The ICO found that, as to MS and three individuals named in the letter, it contained their personal data. Whilst the letter was concerned with performance of their public functions, the professional reputations of two of the third parties were engaged. Disclosure would be unfair, hence would breach the first data protection principle so that the first condition for application of the absolute exemption was satisfied (see FOIA s.40(3)(a)(i)). It would be unfair because the letter was marked "Private and confidential" and referred to matters 
affecting professional reputations and none of the third parties would have reasonably expected its content to be disclosed to the general public.' (Sheaff and The Information Commissioner \& The Department of Health, EA/2014/0005). The Tribunal also explained, 'there is a general expectation that internal staff matters will remain confidential. We do not accept the distinction made by MS between disciplinary issues and other expressions of opinion as to staff members nor the argument that public office holders are not entitled to the same protection of personal data as employees. We find that all concerned reasonably expected that the matters referred to would remain confidential within a limited circle of senior personnel.'

In some respects, the construction of a body of information as being 'personal', and thereby exempt from disclosure, suggests an example of what are described by Lippert, Walby and Wilkinson (2016) as 'spins': 'an effort to redirect or reshape the meaning of particular claims, observations and practices' (2016: 5), Elsewhere (Sheaff, 2019) I refer to this as framing, having consequences not only for disclosure but also contributing to a fragmentation and diminution of accountability. An example relating to the SHA Chair's letter illustrates how the framing of information can place it beyond disclosure. The ICO Decision Notice made reference to redactions under s40(1), as this involved my own personal data. Individual's personal data is exempt from disclosure through FOIA, being accessible instead through a subject access request under the Data Protection Act. So I submitted such a request. Disclosure was however refused by DH, which explained: 'The DPA prevents us from disclosing to you any personal data which is not yours. It also prevents us from breaching any duty of confidentiality owed to any other individuals involved. . . The first bullet point expresses a viewpoint held by another individual at the time of writing and therefore is also their personal data. The Department cannot disclose this without breaching the confidentiality of the individual concerned and consequently disclosure is refused.' (Department of Health, 3 January 2014).

Although insights were provided, it proved far more difficult to use FOIA to explore this example of 'clean-up work' than to examine decision-making concerning the failed contract itself. A significant barrier was the relationship between FOIA and the DPA in the UK, where there has been a notable rise in numbers of FOIA disclosure refusals on the grounds that the material involves 'personal data' (Sheaff, 2019).

\section{FOIA as a tool for Critical Social Research}

The boundary between 'personal' and 'public' information lay at the heart of the dispute over the disclosure of MP's expenses. As noted previously, although it would not have been possible without FOIA disclosures, eventually it was a 'leak' to journalists that allowed wrongdoing to be brought to the attention of the public. Journalism, as Weber discussed in The Profession and Vocation of Politics, can be undervalued, playing as it does a vital role for scrutiny in a democratic society. It can contribute to unveiling 'coverstorying, a term used by Luscombe to refer to, "one mechanism used by state actors to inhibit publics from learning the true nature of their plans, intentions and activities" (Luscombe 2018: 402). Many sociologists might claim a similar role, illustrated in a comment by Keen introducing his FOI-research of FBI surveillance of US sociologists: 'the struggle for democracy, tolerance, and the freedom of speech and dissent, necessary 
for the creative discovery of a vibrant sociological imagination, is a never-ending one which cannot be left untended.' (Keen, 2004: 207).

Shared commitment does not imply a uniform approach. An obvious difference might be that of ethical considerations. As a discussion on reporting of the Watergate scandal noted, 'That documents may be of use to social scientists is one conclusion, but the cultural norms and ethics governing access to documents are quite different for social scientists and for journalists' (Levine, 1980: 628). A century after Weber's observation that, 'it is the irresponsible pieces of journalism that tend to remain in the memory because of their often terrible effects' (Weber in Lassman and Spiers, 1994: 332), ), we learned of revelations in the UK of journalist 'phone-tapping' illustrated, notoriously in the case of Millie Dowler . Transgressions of ethical boundaries need not be as egregious to nevertheless draw an apparent division between journalism and social research. Writing under a pseudonym, 'a journalist working in a senior position in the UK media' emphasises the status of journalism as an art in arguing, 'too many reporters these days confuse the use and management of Freedom of Information requests - and the endless back and forth with the Information Commissioner that often follows - for investigative journalism.' He suggests a quasi-legal 'new style journalism' focuses on revealing secret documents and of railing against "redactions", , but which erodes "the all-important art of contact management: of building a reliable and sympathetic network who will share gossip and, ultimately, leak you information.' He adds, 'too often journalists these days are as expert in the details and mechanisms of FoI law as they are in taking a key contact out for one more pint than he or she might deem sensible. Ultimately this is bad for democracy and for the fourth estate because the FoI Act gives officials the framework to delay and even deny the publication of stuff it doesn't want to get out. There is no such framework to stop the handing over of a brown paper envelope under a pub table.' (Jenkinson, 2007). Writing in the US in the 1960's about what he referred to as 'depth journalism, Copple describes, 'digging out facts beneath the surface. There is no opinion in truly investigative reporting. It resembles a scientific approach' (Copple, 1964: 19). A similar point was made in another, later, US account, describing an increasingly prominent trend during the preceding decade as being, 'the merger between social science methodology' creating, 'a new genre called precision journalism' (Weaver and McCombs, 1980: 477). A classic example of investigative journalism was Bernstein and Woodward's exposure of the Watergate scandal published by the Washington Post, and recounted All the President's Men. Levine (1980), describing their methods as 'more than muckraking', suggests it 'deserves the accolade of art, but there was, in addition, a distinct method to their approach' (Levine, 1980: 626). Noting the challenge of drawing together 'the mass of disconnected pieces of information', Levine puts social research and investigative journalism within the same camp: 'The self-conscious emphasis on controlled and disciplined observation and inference distinguishes the professional researcher from the ordinary citizen' (Levine, 1980: 627).

Since then, several commentators have written of a 'decline of investigative reporting' (e.g. Centre for Investigative Journalism 2018), and others, while detecting 'some reasons to be optimistic', describe it as 'in a fragile state in the UK' (Lashmar, 2013: 37-38). My own research caused me to consider ways in which some of the methods of investigative reporting might align with a sociological inquiry, to develop a more critical analysis of 
state organisations in ways that focused on social and institutional practices. Because these are expressed, through the actions of individuals, I met obstacles when disclosure of information was refused on the grounds that it was 'personal'. Generally, these were not insurmountable, and the MP's expenses case law established that public officials must expect greater scrutiny than private citizens. Piecing together disparate pieces of information from different organisations presented challenges familiar to both social science and journalism.

My interest is in exploring how FOIA might be used to go beyond collecting crossorganisational comparative data to contribute more in-depth analysis of the operation of secrecy (see also Greenberg, this volume). A recent discussion on institutional transparency in the UK notes differences between FOI and transparency programmes more generally. While the former are generally reactive, 'depending upon pressure groups and the public to identify and request information, transparency seeks to be proactive' (Moore, 2018: 420). . Drawing on the work of Simmel, Moore suggests visibility is not the same as intelligibility, and with increasing amounts of data available, the presumption is 'that individuals are best placed to sift the information and decide its uses' (Moore, 2018: 427). Ultimately, she suggests, '21st-century transparency is more likely to calcify than reduce the gap between the public and the state. Refocusing the policy and academic debate to make this a thoroughgoing concern must be the chief task of a new sociology of institutional transparency.' (Moore, 2018: 428).

There is potential for FOIA research to contribute both to visibility and intelligibility, with opportunities to learn from use of FOIA by journalists, to create innovative approaches to examining processes of decision-making beyond the gathering of information. This may be very different to many traditional models of social research, and there can be legitimate concerns about the impact on relationships between the researcher and the public authorities, but these are part of wider sets of relationships, including service users, employees and taxpayers. At a time when many western democracies are experiencing a loss of public trust in traditional institutions, research of this type could make an important contribution to public debate and understanding. Faced with multiple responsibilities, ethical duties are owed not only to the organisation being researched. As acknowledged in a framework for research ethics published by the British Economic and Social Research Council:

'Much social science research has a critical role to play in exploring and questioning social, cultural and economic structures and processes (for example relating to patterns of power and social inequality, and institutional dynamics and regimes that disadvantage some social groups over others, intentionally or not). Such research results may have a negative impact on some of the research participants/organisations.' (Economic \& Social Research Council, 2012: 28)

FOIA offers one route for gaining access to information in these circumstances. Writing in a North American context, Luscombe et al (2017) employ the term 'feral lawyer' to describe citizen-researchers operating in the field of FOI, who are not lawyers but end up 'bargaining, arguing, and appealing in ways familiar to formally trained legal practitioners' (Luscombe et al, 2017: 260). But just as Jenkinson (2017) warned journalists not to be seduced into thinking this is journalism, it represents one element of a research process. The capacity of FOIA research to explore these matters will require not only knowledge of the law but also of the organisations involved. This can attune the 
researcher to the types of questions to be asked and of whom. My own research would not have been possible without the experiences and insights I gained when unsuccessfully attempting to raise questions within the NHS. 'Insider' knowledge of this type may rarely be available directly, but opportunities for collaboration between researchers and others with such knowledge might be fruitful. Trade unions, whistleblowers, campaign groups, and others could be involved in developing a co-operative research focus and approach. FOIA research of this type may not produce quick results, but has a real potential to contribute to a strengthening of transparency and accountability.

\section{References}

Appointments Commission. (2011). Review of the Appointment of xxxx as Chair of xxxx Trust.

Breathnach, A. S., Riley, P. A. \& Planche, T. D. (2011). Use of Freedom of Information Act to produce research on the cheap? British Medical Journal, 343. doi: http://dx.doi.org/10.1136/bmj.d6129 (Published 27 September 2011).

Brignall, M.(2019) Interserve given 'public contracts worth $£ 660 \mathrm{~m}$ in run-up to collapse' The Guardian 18th March 2019

British Sociological Association. (2017). Statement of Ethical Practice for the British Sociological Association. British Sociological Association.

Brown, K. J. (2009). Freedom of Information as a Research Tool: Realising its Potential. The Howard Journal, 48(1), 88-91.

Cabinet Office, FOI Statistics Bulletin 2017. Retrieved from https://assets.publishing.service.gov.uk/government/uploads/system/uploads/attachment_ data/file/704094/foi-statistics-annual-2017-bulletin____.pdf

Campaign for Freedom of Information. (2009). Press Notice, Concern over new Freedom of Information Exemptions.

Centre for Investigative Journalism (2018) Tradecraft and Ideas. https://tcij.org/aboutcij/history/

Chancellor of the Duchy of Lancaster. (1998). Your Right to Know. White Paper. London: The Stationery Office.

Colquhoun, A. (2010). The Cost of Freedom of Information. Constitution Unit, University College London. Retrieved from https://www.ucl.ac.uk/constitutionunit/research/foi/countries/cost-of-foi.pdf

Copple, N. (1964) Depth Reporting. Prentice Hall: Englewood Cliffs, N.J. 
Crossman, R. (1971). The Real English Disease. New Statesman. 24 September, p. 1.

Economic \& Social Research Council. (2012). Framework for Research Ethics (FRE) 2010 Updated September 2012 ESRC.

Fowler, A. J., Agha, R. A., Camm, C. F. \& Littlejohns, P. (2013). The UK Freedom of Information Act (2000) in healthcare research: a systematic review. BMJ Open, e002967. doi:10.1136/bmjopen-2013-002967

House of Lords (2013) The pre-emption of Parliament. Select Committee on the Constitution 13th Report of Session 2012-13. The Stationery Office: London.

Information Commissioner. (2009). House of Commons Ministerial veto on disclosure of Cabinet minutes concerning military action against Iraq Information Commissioner's Report to Parliament. The Stationery Office HC622.

Information Commissioner. (2012). Ministerial veto on disclosure of the Department of Health's Transition Risk Register: Information Commissioner's Report to Parliament. The Stationery Office.

Information Commissioner (2019) The Information Commissioner's written evidence to the Public Administration and Constitutional Affairs Committee's inquiry into sourcing public services: lessons learned from the collapse of Carillion. Information Commissioner's Office.

Lashmar, P (2013). From the Insight Team to Wikileaks, the continuing power of investigative journalism as a benchmark of quality news journalism. In: PJ Anderson, G Ogola \& M Williams (Eds.), The Future of Quality News Journalism: a cross continental analysis. New York: Routledge.

Lassman, P. and Spiers, R. (eds) (1994) Weber: Political Writings. Cambridge: Cambridge University Press.

Levine, M. (1980). 'Investigative reporting as a research method: An analysis of Bernstein and Woodward's All the President's Men'. American Psychologist, 35(7), 626638.

Lippert, RK, Walby, K, Wilkinson, B (2016) Spins, stalls, and shutdowns: Pitfalls of qualitative policing and security research. Qualitative Social Research 17(1): 1-20. Luscombe, A. (2018). Deception Declassified: The Social Organisation of Cover Storying in a Secret Intelligence Operation. Sociology, 52(2), 400-415.

Luscombe, A., Walby, K. \& Lippert, R. K. (2017). Brokering Access Beyond the Border and in the Wild: Comparing Freedom of Information Law and Policy in Canada and the United States. Law \& Policy, 39(3), 259-279. 
Ministry of Justice. (2009). Exercise of the Executive Override in respect of the decision of the Information Commissioner FS50165372 as upheld by the decision of the Information Tribunal EA/2008/0024 \& EA/2008/0029. Statement of Reasons.

Moore, S. (2018). Towards a Sociology of Institutional Transparency: Openness, Deception and the Problem of Public Trust. Sociology, 52(2), 416-430.

Murray, C. (2013). Sport in Care: Using Freedom of Information Requests to Elicit Data about Looked After Children's Involvement in Physical Activity. British Journal of Social Work, 43(7), 1347-1363

National Audit Office (2018) Investigation into the government's handling of the collapse of Carillion. Cabinet Office: London.

Rosenbaum. (2009, June 10). Two Government plans FOI restrictions. BBC Open Secrets. Retrieved from http://www.bbc.co.uk/blogs/opensecrets/2009/06/government_plans_foi_restrictions.html

Savage, A. \& Hyde, R. (2014). Using freedom of information requests to facilitate research, International Journal of Social Research Methodology, 17(3), 303-317.

Sheaff, M. (2017). Constructing accounts of organisational failure: Policy, power and concealment. Critical Social Policy, 37(4), 520-539.

Sheaff, M. (2016). On the Frontline: Challenging Secrecy in the NHS Through Research Discover Society

Sheaff, M. (2019) Secrecy, Privacy and Accountability: Challenges for Social Research. Palgrave Macmillan: Cham, Switzerland.

UK Supreme Court. (2015). Judgment: R (on the application of Evans) and another (Respondents) v Attorney General (Appellant). UKSC 21. On appeal from (2014) EWCA Civ 254.

Vaughan, D. (1996). The Challenger Launch Decision. Chicago: University of Chicago Press.

Weaver, D.H. and McCombs, M.E. (1980) 'Journalism and Social Science: A New Relationship?' The Public Opinion Quarterly, Vol. 44, No. 4, Polls and the News Media: A Symposium (Winter, 1980), pp. 477-494 